\title{
ANNOUNCEMENT / COMMUNIQUÉ
}

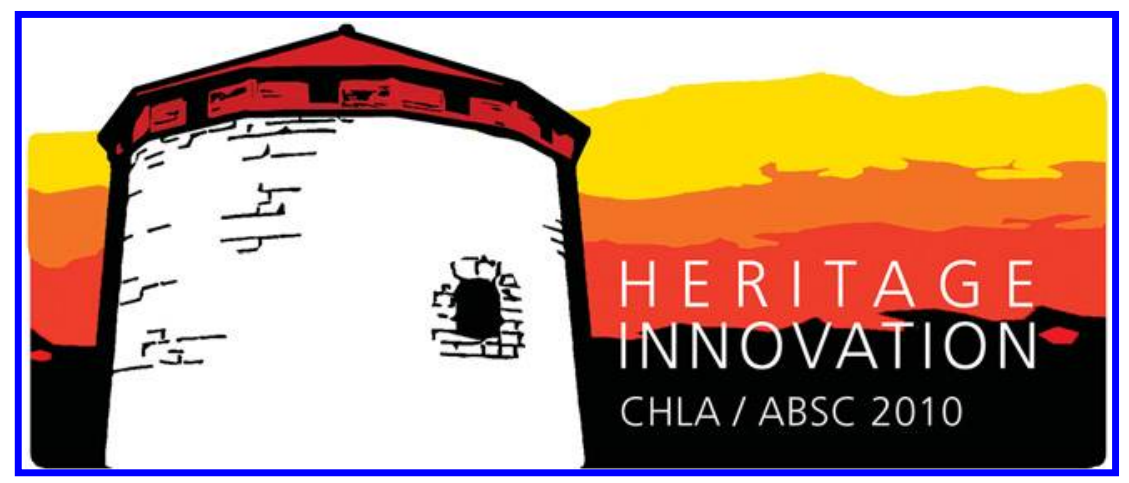

\section{Heritage and innovation converge at CHLA / ABSC 2010 in Kingston! 7-11 June 2010}

The 34th annual conference of the Canadian Health Libraries Association / Association des bibliothèques de la santé du Canada (CHLA / ABSC) takes place in historic Kingston, Ontario, in June 2010. Join us in Canada's first capital city and home of our first Prime Minister, Sir John A. MacDonald, for a stimulating program that will engage, inform, challenge, and inspire you. Our theme, Honouring Heritage / Inspiring Innovation, invites reflection on our past successes while we create an exciting future for health libraries and librarians.

The conference will begin with a solid line-up of nine half-day continuing education (CE) courses taught by experts in their fields. CE course offerings are on a wide range of topics, and there is something for everyone: Searching Skills for Systematic Reviews, Libraries and Patient Safety, Copyright, Facilitating Effective Learning, Fundraising, Image and Presence Building, Health Patents, Government Documents and Statistics, and Expert PubMed Searching.

Each day, one of our plenary speakers, Dr. Jacalyn Duffin (Hannah Chair for the History of Medicine at Queen's University), Dr. Brian Little (personality psychologist, Affiliated Scholar at the Radcliffe Institute for Advanced Study at Harvard University and Distinguished Research Professor in Psychology at Carleton University), and Dr. Udo Schüklenk (Professor of Philosophy and Ontario Research Chair in Bioethics at Queen's University), will provide a thought-provoking and informative talk. Contributions from our colleagues through poster and paper presentations as well as roundtable discussions will demonstrate the breadth of knowledge, skills, and leadership that are so strong in our health libraries community.

On the social side of things, CHLA / ABSC 2010 will offer many opportunities for networking, meeting new people, and catching up with friends. For the hardy (and early risers), there will be guided morning walks each day before the conference program commences. The opening reception will be held in Memorial Hall in historic Kingston City Hall, just around the corner from the conference hotel, the Four Points Sheraton. The annual banquet will be held at the Vimy Officers' Mess at Canadian Forces Base Kingston. Prior to dinner, you will be able to enjoy the lovely view of the St. Lawrence River from the patio. Tours are also on the agenda, including the Museum of Health Care and the Agnes Etherington Art Centre, plus a very special post-conference tour and dinner on the "Taste Trail" in nearby Prince Edward County.

Visit the conference Web page at http://www.chla-absc. $\mathrm{ca} / 2010 /$ often for current information and conference updates.

We look forward to welcoming you to Kingston in June!

\section{Laurie Scott}

Chair

Kingston 2010 Conference Planning Committee

Queen's University

Bracken Health Sciences Library

Room 130, Botterell Hall

Kingston, ON K7L 3N6, Canada

E-mail:laurie.scott@queensu.ca 